\title{
A further study of air pollution in diesel bus garages
}

\author{
R E WALLER, L HAMPTON, AND P J LAWTHER \\ From the MRC Toxicology Unit (Clinical Section), * St Bartholomew's Hospital Medical College, London, UK
}

ABSTRACT The concentrations of smoke, polycyclic aromatic hydrocarbons (PAHs), and some $\frac{\mathscr{N}}{\circ}$ gaseous air pollutants have been measured in two London Transport diesel bus garages and compared with observations made in the same garages over 20 years earlier. The main feature of the $\vec{\omega}$ results was a large reduction in the background concentrations of smoke and polycyclic aromatic hydrocarbons from sources such as coal fires, attributable to the implementation of the Clean Air $\frac{\mathbb{D}}{3}$ Act. Contributions from the buses to the benzo(a) pyrene content of the air inside the garages were of the same magnitude as before, being small in relation to former coal smoke contributions.

In an earlier paper ${ }^{1}$ we reported on observations of smoke, polycyclic aromatic hydrocarbons, and some other air pollutants made in two London Transport bus garages. There was concern then about the possible role of diesel smoke in the development of lung cancer, although no excess incidence of the disease was seen among garage workers at that time. ${ }^{2}$ Our early studies had shown that whereas the manoeuvring of buses in poorly ventilated garages led to substantial increases in the concentrations of black smoke, as compared with the background from other sources, concentrations of polycyclic aromatic hydrocarbons, including the potentially carcinogenic benzo(a)pyrene, were not enhanced appreciably. The situation then was that in the winter months concentrations of these compounds were dominated by emissions from domestic coal fires. Even in April and October we found it difficult to discern any effect of the buses on the concentrations of benzo(a)pyrene in the garages and we had to repeat the studies in midsummer in order to make improved assessments.

Since then many of the circumstances have changed, and to provide some link with the continuing study of the incidence of lung cancer among the staff the opportunity has been taken to return to the same two garages and to repeat the same types of observations that had been made more than 20 years earlier. The main difference expected was a substantially reduced background of smoke and polycyclic aromatic hydrocarbons from coal fires after the implementation of the Clean Air Act. The types of buses

*This work was done before the disbandment of the clinical section of the unit.

Received 25 March 1985

Accepted 15 April 1985 in service, the numbers using each garage, and the $\stackrel{N}{\rightarrow}$ general operating procedures had also changed.

\section{Sampling sites}

A preliminary inspection was again made of each garage to determine where the highest pollution $\mathbb{D}$ might occur. At Merton (fig 1) it was decided to locate $\overrightarrow{0}$ the main samplers close to the entrance (site A) beftor directly opposite the site used previously. This wass because the installation of an automatic washiogo plant had diverted the main flow of buses in the evening towards the left hand side of the garage on entry. They still stopped at that point for refuelling $\frac{\mathrm{Q}}{\varnothing}$ and interior vacuum cleaning, but the exhaust pipes $\varrho$ were on the off side, directed away from the samplers. $\vec{B}$ This was, however, where some men were likely to be exposed, and in the run-out in the morning buses again stopped there for radiators to be topped up, with exhaust pipes then directed towards the sam-O plers. A supplementary site was again set up in the 3 annex (site B), particularly to examine pollution dur-o ing the morning run-out. One change affecting that part of the garage was that the existing rear doorso were opened more, as some buses now left by that route, and additional doors had been fitted to provideo access to open parking space. The site chosen (B) was a short distance from the one used previously, but in an analogous position. The control site (C) outside the garage was located on the roof as before, and the remaining dispersed sites used for small samplers o were also in the same positions $(\mathrm{D}$, inside the conduc-N tors' office, and E, by the dock, where maintenance work was carried out during the day).

At Dalston the operating procedures had changed? even more, since buses entered through the rear doorson 


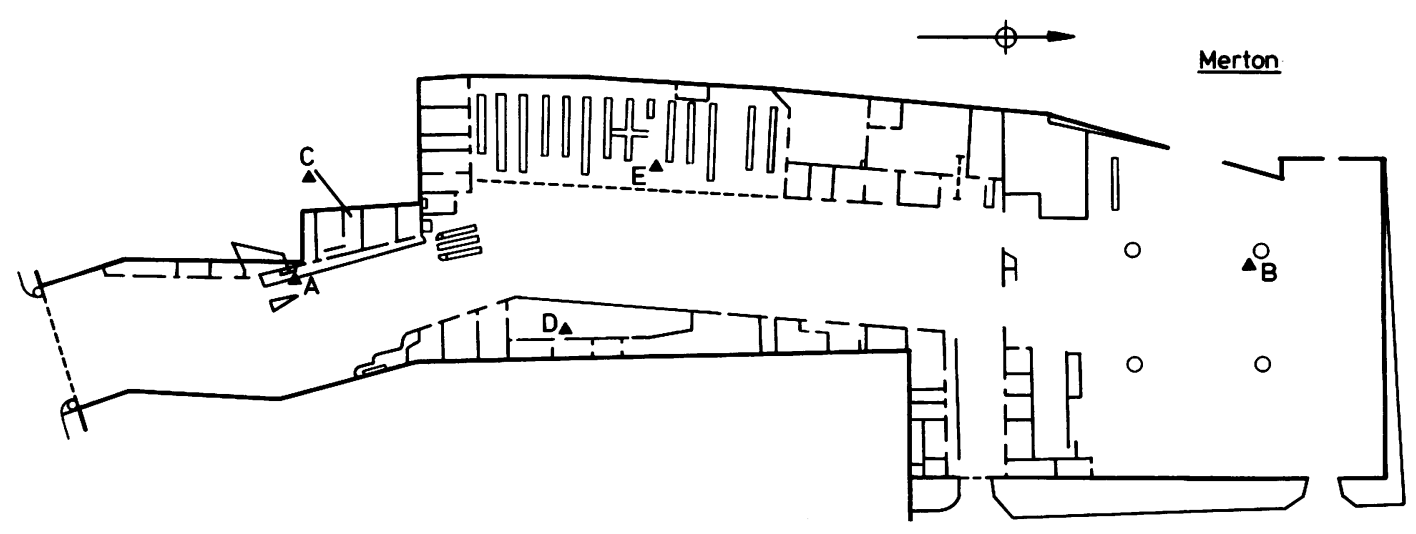

Fig 1 Plan of Merton garage showing sampling sites at entrance $(A)$, annex $(B)$, roof $(C)$, office $(D)$ and dock $(E)$.

instead of the main ones as before, and refuelling and vacuum cleaning was done there. The main sampling site was therefore set up close to the point where buses stopped (P, fig 2$)$, with a supplementary point for use during the morning run-out in the corner of the garage $(\mathrm{Q})$, close to the site used before. The control site outside (R) was on the roof still, and the other sites ( $\mathrm{S}$, conductors' office and $\mathrm{T}$, dock) were in similar positions to those used earlier.

\section{Methods}

The intention was to repeat the procedures followed in earlier studies as closely as possible, and thus the same basic sampling instruments and analytical methods were used, even though there had been substantial developments in instrumentation and techniques since then. Similarly, the aim was to examine the distribution of pollutants for one repre-

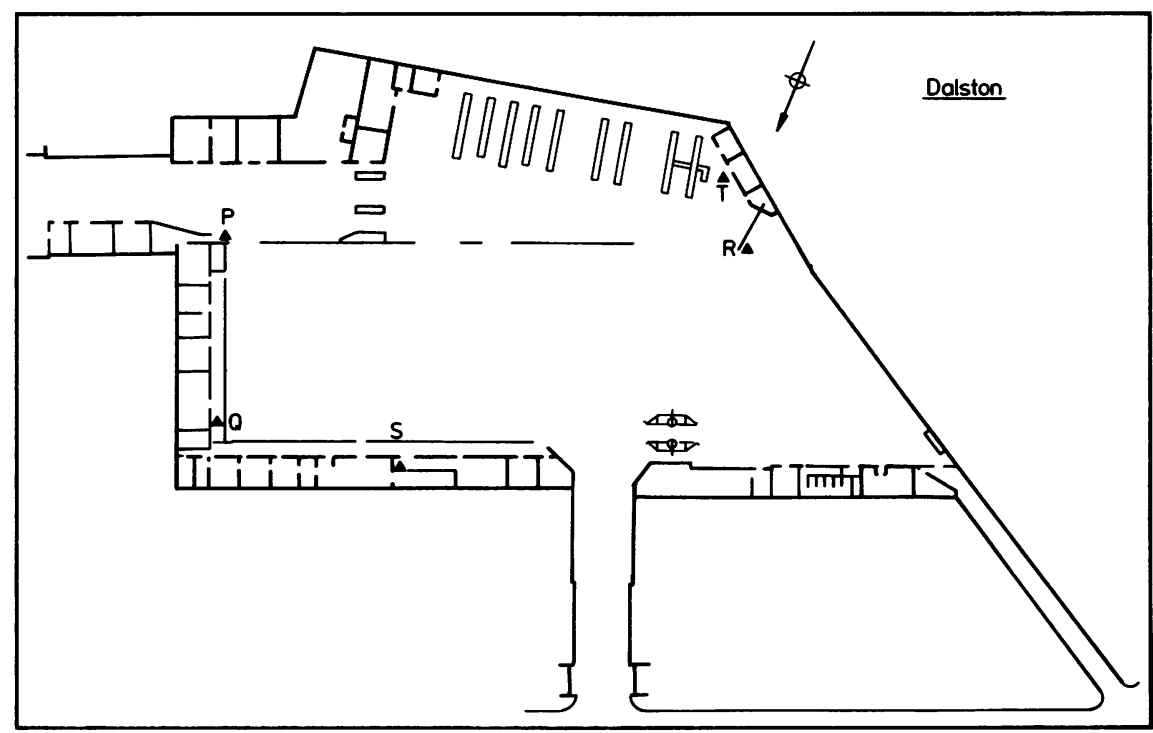

Fig 2 Plan of Dalston garage showing sampling sites, at entrance $(P)$, corner $(Q)$, roof $(R)$, office $(S)$ and dock $(T)$. 
sentative day in each garage rather than to determine long term mean values. The days chosen were normal weekdays, and to ensure a minimal background from heating sources, mid-summer was selected. As before, emissions of pollution within the garages occurred mainly in the late evening and the early morning, when most buses entered and left the garages, and sampling periods were arranged to cover these. As more buses now moved in and out of the garages during the day additional sampling periods were added at the beginning and end so as to cover the full 24 hour cycle of events (table 1).

Table 1 Arrangement of sampling periods in bus garages

\begin{tabular}{|c|c|c|}
\hline Period & Time $(h)$ & Activity \\
\hline 0 & $1300-1800$ & $\begin{array}{l}\text { Buses entering and leaving } \\
\text { garage occasionally }\end{array}$ \\
\hline 1 & $1800-2300$ & $\begin{array}{l}\text { Buses returning to garage for } \\
\text { the night, refuelled and cleaned } \\
\text { on entry }\end{array}$ \\
\hline 2 & $2300-0100$ & $\begin{array}{l}\text { Final run-in, refuelling, cleaning, } \\
\text { and shunting into place }\end{array}$ \\
\hline 3 & $0100-0500$ & No buses moving \\
\hline 4 & $0500-0900$ & $\begin{array}{l}\text { Main run-out: buses leaving garage, } \\
\text { stopping for radiator top up }\end{array}$ \\
\hline 5 & $0900-1300$ & $\begin{array}{l}\text { Buses entering and leaving } \\
\text { garage occasionally }\end{array}$ \\
\hline
\end{tabular}

The main samples for the determination of concentrations of smoke and polycyclic aromatic hydrocarbons were collected on weighed glass fibre filter sheets measuring 8 in $\times 10$ in $(20 \mathrm{~cm} \times 25 \mathrm{~cm})$ overall by means of a Staplex high volume sampler, at a rate of about $1.4 \mathrm{~m}^{3} / \mathrm{min}$.

At sites A (Merton) and P (Dalston), two such samplers were used side by side for each of the five periods to provide some check on reproducibility. A single high volume sampler was run at sites B (Merton) and $\mathrm{Q}$ (Dalston) during period 4 (early morning run-out) only.

Concentrations of smoke were also examined simultaneously in two other ways. At each of the five dispersed sites in each garage a low rate gravimetric sampler was set up, in which smoke was collected on to a glass fibre filter in an open filter holder with an exposed area 2 in $(5 \mathrm{~cm})$ diameter. The sampling rate was about $61 / \mathrm{min}$, and each filter was run for a single 24 hour period. A standard smoke/ $\mathrm{SO}_{2}$ sampler of the type used in the National Survey was also set up alongside each of these latter filters. This comprised a Whatman filter paper of 2 in $(5 \mathrm{~cm})$ exposed area in a closed holder, with a bubbler containing dilute $\mathrm{H}_{2} \mathrm{O}_{2}$ for the determination of $\mathrm{SO}_{2}$.

The sampling rate was about $1.5 \mathrm{l} / \mathrm{min}$ and each sample covered a single 24 hour period. Smoke concentrations were assessed by reflectance using the standard calibration (recognising that it may not give a true equivalent weight of smoke for the material collected in and around the garage). To provide a $\overline{\bar{\alpha}}$ visual indication of peaks in smoke concentration as $\bar{z}$ buses passed, a continuous sampler was also used at $\stackrel{\mathbb{Q}}{0}$ sites $\mathbf{A}$ and $\mathbf{P}$, in which smoke was collected on a strip of Whatman No 1 paper.

Additional instruments were installed at the main sampling sites to assess transient peaks in gaseous 음 pollutants. Sulphur dioxide was measured with a fast $\frac{\bar{\omega}}{\partial}$ response monitor based on the conductivity prin- $\Phi$ ciple, ${ }^{3}$ carbon monoxide with an electrochemical instrument, oxides of nitrogen with a chemiluminescent analyser, and the outputs were connected to a multi- $\vec{\circ}$ channel recorder, so that changes could be observed $\vec{F}$ on a common time base. At Merton all these instru- $\mathscr{O}$ ments were housed in an office alongside site $A$ and $\bigcirc$ the inlets were at breathing level a short distance from 3 the particulate samplers. At Dalston all the instru- $\frac{\vec{N}}{\mathrm{~N}}$ ments were grouped together at site $P$.

After collection, each of the (high volume) glass $\vec{N}$ fibre filters was weighed and extracted with cy- N clohexane in a Soxhlet apparatus for eight hours. The resulting solution was reduced to small bulk, made up $\frac{}{J}$ to a standard volume, and an aliquot of this was transferred to an alumina column. The hydrocarbons $\mathbb{D}$ were separated by elution with cyclohexane and determined spectrophotometrically, as in our earlier studies. $^{4}$

\section{Results}

The main results from the high volume samples a summarised in tables 2 and 3 . There were no substantial differences between findings from the duplicate filters run at sites $A$ and $P$, and the figures shown in $\frac{O}{D}$ the tables are the means for each pair of filters. At no $\unrhd$ time were the concentrations of smoke and polycyclic $\overrightarrow{\vec{O}}$ hydrocarbons as high as had been seen in the earlier 3 series, but the distribution during the day differed, with the highest values now occurring during the morning run-out (period 4) rather than in the evening $O$ run-in (periods 1 or 2 ). This no doubt reflected $\frac{\Phi}{3}$ changes in operating procedures, for the build up of 0 buses waiting with engines running to be washed 3 manually as they came in was now avoided. The addi- $\delta$ tional sites $B$ and $Q$ had been set up in places considered to be particularly affected by pollution during 0 the morning run-out. At Merton smoke concentrations were certainly higher at $B$ than at $A$, though A retained the higher hydrocarbon concentrations. At Dalston $Q$ was more polluted by both smoke and 0 hydrocarbons than P. Pollution was more uniformly N distributed during the day than before, probably as a N result of the greater spread of bus movements. A no- $O$ table feature was the relatively low background concentrations of smoke at the roof sites (C and R) compared with those in the earlier series, and the low $ᄋ$ 
Table 2 Concentrations of smoke and polycyclic hydrocarbons at Merton garage, 20-21 June 1979

\begin{tabular}{|c|c|c|c|c|c|c|c|c|}
\hline \multirow[t]{2}{*}{ Period } & \multirow[t]{2}{*}{ Site } & \multirow{2}{*}{$\begin{array}{l}\text { Smoke } \\
\left(\mu g / m^{3}\right)\end{array}$} & \multicolumn{6}{|c|}{ Polycyclic hydrocarbons $\left(\mu \mathrm{g} / 1000 \mathrm{~m}^{3}\right)$} \\
\hline & & & $\overline{P Y R}$ & $\mathrm{BeP}$ & $B a P$ & $B p$ & $A N T H$ & $C O R$ \\
\hline $\begin{array}{l}0 \\
1 \\
2 \\
3 \\
4 \\
5 \\
4 \\
0-5\end{array}$ & $\stackrel{\mathbf{B}}{\mathbf{C}}$ & $\begin{array}{r}800 \\
730 \\
780 \\
173 \\
584 \\
614 \\
1143 \\
138\end{array}$ & $\begin{array}{r}16.2 \\
16.3 \\
18.6 \\
2.5 \\
17.5 \\
17.6 \\
29.0 \\
0.9\end{array}$ & $\begin{array}{r}7.8 \\
6.8 \\
7.4 \\
1.2 \\
11.6 \\
8.4 \\
10.0 \\
0.7\end{array}$ & $\begin{array}{r}6.8 \\
6.9 \\
5.9 \\
0.6 \\
13.0 \\
5.8 \\
14.0 \\
0.3\end{array}$ & $\begin{array}{r}19.4 \\
14.0 \\
10.6 \\
1.1 \\
27.2 \\
18.4 \\
14.0 \\
1.2\end{array}$ & $\begin{array}{l}2.5 \\
1.8 \\
1.8 \\
0.05 \\
4.5 \\
2.6 \\
2.0 \\
0 \cdot 1\end{array}$ & $\begin{array}{r}10.4 \\
5.9 \\
7.4 \\
0.8 \\
13.6 \\
8.8 \\
7.0 \\
0.5\end{array}$ \\
\hline
\end{tabular}

Merton $\mathrm{A}=$ main site, entrance, $\mathrm{B}=$ annex, $\mathrm{C}=$ roof (outside)

Dalston $P=$ main site, entrance, $Q=$ corner of garage, $R=$ roof (outside).

PYR = Pyrene

BeP = Benzo(e)pyrene (1:2-benzpyrene)

$\mathrm{BaP}=$ Benzo(a)pyrene (3:4-benzpyrene)

Bp $=$ Benzo(ghi)perylene (1:12-benzperylene)

ANTH = Anthanthrene

$\mathrm{COR}=$ Coronene

Table 3 Concentrations of smoke and polycyclic hydrocarbons at Dalston garage, 17-18 July 1979

\begin{tabular}{|c|c|c|c|c|c|c|c|c|}
\hline \multirow{2}{*}{$\begin{array}{l}\text { Period } \\
\text {. }\end{array}$} & \multirow[t]{2}{*}{ Site } & \multirow{2}{*}{$\begin{array}{l}\text { Smoke } \\
\left(\mu \mathrm{g} / \mathrm{m}^{3}\right)\end{array}$} & \multicolumn{6}{|c|}{ Polycyclic hydrocarbons $\left(\mu \mathrm{g} / 1000 \mathrm{~m}^{3}\right)$} \\
\hline & & & $\overline{P Y R}$ & $\mathrm{BeP}$ & $B a P$ & $B p$ & $A N T H$ & COR \\
\hline $\begin{array}{l}0 \\
1 \\
2 \\
3 \\
4 \\
5 \\
4 \\
0-5\end{array}$ & $\begin{array}{l}\mathbf{Q} \\
\mathbf{R}\end{array}$ & $\begin{array}{r}154 \\
192 \\
105 \\
47 \\
148 \\
327 \\
356 \\
33\end{array}$ & $\begin{array}{l}1.0 \\
1.7 \\
1.4 \\
0.4 \\
0.8 \\
1.9 \\
2.2 \\
0.2\end{array}$ & $\begin{array}{l}1.0 \\
2.0 \\
0.8 \\
0 \cdot 1 \\
2.0 \\
2.4 \\
4.9 \\
0.2\end{array}$ & $\begin{array}{l}0.8 \\
1.2 \\
1.2 \\
0.4 \\
0.9 \\
2.3 \\
6.0 \\
0.1\end{array}$ & $\begin{array}{l}3.8 \\
4.2 \\
1.9 \\
0.7 \\
5.4 \\
5.5 \\
9.1 \\
0.6\end{array}$ & $\begin{array}{l}0 \cdot 2 \\
0 \cdot 4 \\
0 \cdot 3 \\
0 \cdot 1 \\
0 \cdot 2 \\
0.6 \\
1 \cdot 2 \\
0.02\end{array}$ & $\begin{array}{l}2.6 \\
1.8 \\
1.6 \\
0.6 \\
1.5 \\
2.5 \\
3.2 \\
0.3\end{array}$ \\
\hline
\end{tabular}

See table 2 .

concentrations of polycyclic aromatic hydrocarbons there. During the night (period 3) when no buses were moving, the concentrations of smoke and hydrocarbons in the garages were similar to those at the roof sites.

As before, pollution tended to be less in Dalston than in the much busier Merton garage.

Because of the low background pollution from coal fires now, contributions from the buses within the garage stood out more clearly than before, though this did not necessarily mean that they were any greater.

- In tables 4 and 5 these contributions have been estimated by subtracting the corresponding background values (sites $\mathbf{C}$ and $\mathbf{R}$ ). The figures are approximate, since any variation in background during the day had to be ignored. Figures derived from the summer samples in the earlier series have been added for comparison. Broadly speaking, the contribution from the buses could be said to be of the same order of magnitude as before. At Merton, while a reduced contribution during the evening run-in (periods 1 and 2) was evident, that at site B during the morning run-out was higher, and roughly equivalent to the evening peak before.
Table 4 Estimated contributions by buses to the smoke and benzo(a) pyrene content of the air in Merton garage

\begin{tabular}{lccccc}
\hline Period & Site & \multicolumn{2}{c}{ Smoke $\left(\mu \mathrm{g} / \mathrm{m}^{3}\right)$} & \multicolumn{2}{c}{$B a P\left(\mu \mathrm{g} / 1000 \mathrm{~m}^{3}\right)$} \\
\cline { 3 - 6 } & & June & June & June & June \\
& & 1956 & 1979 & 1956 & 1979 \\
\hline 0 & $\mathrm{~A}$ & - & 622 & - & 6.5 \\
1 & & 570 & 592 & 12 & 6.4 \\
2 & & 1210 & 642 & 12 & 5.6 \\
3 & & 30 & 35 & 0 & $0 \cdot 3$ \\
4 & & - & 446 & - & 12.7 \\
5 & & - & 276 & - & 5.5 \\
4 & B & 340 & 1005 & 0 & 13.7 \\
\hline
\end{tabular}

$\mathrm{BaP}=$ Benzo(a)pyrene (3:4-benzpyrene).

Clearly the buses lead to substantially enhanced smoke concentrations in the garages (more notably at Merton than at Dalston) and the contributions to the polycyclics, although no greater than before, are by now quite substantial in relation to the (greatly reduced) background. It remains true, however, that the polycyclic content of the smoke as emitted by the buses is low compared with that from coal fires. This feature is brought out in tables 6 and 7 , in which (as an example) the benzo(a)pyrene content of the smoke 
Table 5 Estimated contributions by buses to the smoke and benzo(a) pyrene content of the air in Dalston garage

\begin{tabular}{llllll}
\hline Period & Site & \multicolumn{2}{c}{ Smoke $\left(\mu \mathrm{g} / \mathrm{m}^{3}\right)$} & \multicolumn{2}{c}{$B a P\left(\mu \mathrm{g} / 1000 \mathrm{~m}^{3}\right)$} \\
\cline { 3 - 6 } & & June & July & June & July \\
& & 1957 & 1979 & 1957 & 1979 \\
\hline 0 & $\mathrm{P}$ & - & 121 & - & 0.7 \\
1 & & 290 & 159 & 2 & 1.1 \\
2 & & 150 & 72 & 4 & 1.1 \\
3 & & 80 & 14 & 0 & 0.3 \\
4 & & - & 115 & - & 0.8 \\
5 & & 294 & - & 2.2 \\
4 & $\mathrm{Q}$ & 290 & 323 & 17 & 5.9 \\
\hline
\end{tabular}

$\mathrm{BaP}=$ Benzo(a)pyrene (3:4-benzpyrene).

Table 6 Benzo(a)pyrene content of the smoke at Merton garage $(\mu \mathrm{g} / \mathrm{g})$

\begin{tabular}{lllll}
\hline Period & Site & $\begin{array}{c}\text { April } \\
1956\end{array}$ & $\begin{array}{c}\text { June } \\
1956\end{array}$ & $\begin{array}{c}\text { June } \\
1979\end{array}$ \\
\hline 0 & A & - & - & 8 \\
1 & & 155 & 33 & 9 \\
2 & & 151 & 18 & 8 \\
3 & & 273 & 52 & 3 \\
4 & & - & - & 22 \\
5 & B & 157 & 10 & 9 \\
4 & C & $355^{*}$ & $66^{*}$ & 12 \\
$0-5$ & & & 2 \\
\hline
\end{tabular}

*Mean values for available periods (1-4).

Table 7 Benzo(a)pyrene content of the smoke at Dalston garage $(\mu \mathrm{g} / \mathrm{g})$

\begin{tabular}{|c|c|c|c|c|}
\hline Period & Site & $\begin{array}{l}\text { Oct } \\
1956\end{array}$ & $\begin{array}{l}\text { June } \\
1957\end{array}$ & $\begin{array}{l}\text { July } \\
1979\end{array}$ \\
\hline $\begin{array}{l}0 \\
1 \\
2 \\
3 \\
4 \\
5 \\
4 \\
0-5\end{array}$ & $\begin{array}{l}\mathbf{Q} \\
\mathbf{R}\end{array}$ & $\begin{array}{c}\overline{110} \\
92 \\
138 \\
\overline{-} \\
54 \\
151^{*}\end{array}$ & $\begin{array}{l}\overline{53} \\
33 \\
21 \\
\overline{-} \\
64 \\
70^{*}\end{array}$ & $\begin{array}{r}5 \\
6 \\
11 \\
9 \\
6 \\
7 \\
17 \\
3\end{array}$ \\
\hline
\end{tabular}

*Mean values for available periods (1-4).

collected in each period in the recent series is shown along with corresponding figures from both the summer and the near winter (April, October) samples.

The highest figure is the one for the background site (C) at Merton in April 1956, when there were high concentrations of coal smoke from domestic chimneys nearby, and this figure is similar to that seen in a coal mining area during winter in still earlier studies of benzo(a)pyrene in urban air. ${ }^{5}$ The generally lower figures within the garages (as compared with outside) in the 1956-7 series indicate that the diesel smoke was relatively weak in benzo(a)pyrene, producing a diluting effect on the background material. By 1979 the tables had been turned, for the background material was then extremely weak in benzo(a)pyrene, and whereas there was still apparently little in the diesel $\overline{\bar{\alpha}}$ smoke it was sufficient to enrich the background ma- $\frac{z}{z}$ terial slightly, a little more in the morning run-out $\stackrel{\otimes}{\circ}$ (period 4, site A, at Merton and site $Q$ at Dalston) than at other times. All these calculations may be $\overrightarrow{\vec{S}}$ taken a stage further, to derive "richness" figures in $\mu \mathrm{g} / \mathrm{g}$ for the contributions from the buses (tables 4 듬 and 5), but they then depend on the somewhat uncer- $\bar{\omega}$ tain estimates by difference. Such figures, however, fall mainly in the range $10-20 \mu \mathrm{g} / \mathrm{g}$, which is much weaker than the $100-300 \mu \mathrm{g} / \mathrm{g}$ common in coal ${ }^{\circ}$ smoke.

The additional low rate samplers were run primarily to check the distribution of smoke around the $\vec{\omega}$ garages, and they were not analysed for hydrocarbons. A summary of results is shown in tables $8 \frac{\mathbb{D}}{3}$ and 9, together with weighted mean values for the accompanying high volume samples where applica- ? ble. Comparison of smoke concentrations between $\vec{N}$ sites is best based on the (low rate) gravimetric results. At Merton these indicate that the sites chosen for the main samplers ( $P$ and $\mathbf{Q})$ did have the highest concentrations, when averaged over the complete 24 hours, though those in the office and dock were not far behind. The results assessed by reflectance relate particularly to the black component, and the ratio of 3 the reflectance to the gravimetric result gives an indi- 음 cation of the extent to which black smoke is dominant $\vec{\theta}$ in the sample (diesel smoke being especially black io relation to its weight). Thus the proportion of diese smoke appeared to be higher at the dock site that anywhere else, whereas it was relatively low in the office, where cigarette smoke was an important contaminant. At the roof site there was also a substantial proportion of non-black material, from general urban sources, and the higher result obtained with the high volume sampler indicates that some relatively coarse dust, beyond the respiratory range, was present there. Similarly, there was some coarse component at the main site (A).

At Dalston the sites chosen for the main samples ( $P$ and $Q$ ) proved not to have the highest concentrations of smoke over the 24 hours as a whole, though it had been evident at the time that they were the ones most subject to intermittent periods of high pollution. Again cigarette smoke would have had some effect on the concentration as determined gravimetrically at the office site, but black smoke was an appreciable component there and the "blackest" smoke appeared to be at site $Q$ in the corner of the garage which received emissions from buses being manoeuvred in and out of the tight parking in that area. There was, however, nowhere in Dalston garage as polluted as some of the sites at Merton, and although the concentrations of smoke, as measured by any of the three methods, were all above the (low) background levels 
on the day in question, they were within the range commonly found in urban air in other seasons.

Concentrations of sulphur dioxide as shown in tables 8 and 9 were not substantially above background levels (as measured at sites $C$ and $R$ ). At Merton there was some enhancement at sites $A$ and $E$ that could be attributed to emissions from the buses, but in the office there was a deficit, due to absorption on clothes, walls, and other surfaces in this relatively confined space, or to some neutralisation by ammonia. All the $\mathrm{SO}_{2}$ was absorbed or neutralised in the office at Dalston, and only the dock site showed any excess over background.

Although emissions from the buses had little effect on the mean concentrations of $\mathrm{SO}_{2}$ there were transient peaks that could be detected close to the vehicles, and the continuous instrument showed values around $500 \mu \mathrm{g} / \mathrm{m}^{3}$ as buses passed the sampling site (A) at Merton, with occasional maxima of about 1000 $\mu \mathrm{g} / \mathrm{m}^{3}$. At Dalston values were generally lower, with maxima around $350 \mu \mathrm{g} / \mathrm{m}^{3}$. Peaks of these magnitudes can occur in the general urban air as plumes from nearby chimneys serving heavy oil or coal fired heating plants blow across a sampler or in calm weather when such pollution accumulates.

Despite emissions of carbon monoxide being low from diesel (as opposed to petrol) vehicles, many of the buses that passed the sampling points produced a small momentary increase in concentration, usually up to about $10 \mathrm{ppm}$, with maxima of $20 \mathrm{ppm}$ at Dalston (site P) and $70 \mathrm{ppm}$ at Merton (site A). The more notable peaks in CO came, however, from private cars belonging to the staff that occasionally entered and left the garages (no cars entered during the earlier series in the 1950s but with fewer buses now, some are allowed in). In general the $\mathrm{CO}$ concentrations in the garage could be said to be less than those outside in a busy street.

The measurements of oxides of nitrogen proved unsatisfactory due to failure of components during transit in the initial sampling periods, but return visits were made later with a more portable instrument. Even then it was difficult to assess transient peaks of $\mathrm{NO}_{2}$ adequately, since values were obtained by difference from sample lines that were successively measuring $\mathrm{NO}$ and $\mathrm{NO}+\mathrm{NO}_{2}$ (the $\mathrm{NO}_{2}$ being reduced back to NO). When sampling close to the buses as they passed, concentrations varied too rapidly for such a difference method to give true results for $\mathrm{NO}_{2}$.

Subject to these reservations the results indicated average values at sites $A$ and $P$ of about $0.5 \mathrm{ppm}$ for $\mathrm{NO}$ and about $0.3 \mathrm{ppm}$ for $\mathrm{NO}_{2}$ during active periods when buses were passing regularly, with occasional transient peaks up to about $4 \mathrm{ppm}$ for NO and 2.5 ppm for $\mathrm{NO}_{2}$ when buses were idling nearby with exhausts directed towards the intake. Similar situations might be met in streets close to traffic (either diesel or petrol engined), and concentrations of similar orders of magnitude are liable to occur indoors when influed gas or kerosene applicances are in use. ${ }^{6}$

\section{Discussion}

The major change in pollution at the bus garages over the 23 year interval between our two series of studies is related to external rather than internal sources. The implementation of the Clean Air Act has led to a dramatic reduction in concentrations of smoke and the

Table 8 Summary of smoke and sulphur dioxide concentrations at dispersed sites in Merton garage, 20-21 June 1979

\begin{tabular}{|c|c|c|c|c|c|c|}
\hline Site & & $\stackrel{A}{\text { Entrance }}$ & $\begin{array}{l}B \\
\text { Annex }\end{array}$ & $\begin{array}{l}\text { C } \\
\text { Roof }\end{array}$ & $\begin{array}{l}D \\
\text { Office }\end{array}$ & $\begin{array}{l}E \\
\text { Dock }\end{array}$ \\
\hline $\begin{array}{l}\text { Smoke }\left(\mu \mathrm{g} / \mathrm{m}^{3}\right) \\
\mathrm{SO}_{2}\left(\mu \mathrm{g} / \mathrm{m}^{3}\right)\end{array}$ & $\begin{array}{l}\text { (HVS } \\
\text { (Gravimetric } \\
\text { (Reflectance } \\
\text { Titration }\end{array}$ & $\begin{array}{l}612 \\
510 \\
327 \\
154\end{array}$ & $\begin{array}{r}- \\
542 \\
154 \\
79\end{array}$ & $\begin{array}{r}138 \\
69 \\
17 \\
73\end{array}$ & $\begin{array}{r}- \\
417 \\
125 \\
26\end{array}$ & $\begin{array}{l}\overline{355} \\
340 \\
125\end{array}$ \\
\hline
\end{tabular}

HVS = High volume samples: weighted means of figures from table 2.

Table 9 Summary of smoke and sulphur dioxide concentrations at dispersed sites in Dalston garage, 17-18 July 1979

\begin{tabular}{|c|c|c|c|c|c|c|}
\hline Site & & $\begin{array}{l}P \\
\text { Entrance }\end{array}$ & $\stackrel{Q}{\text { Corner }}$ & $\begin{array}{l}R \\
R o o f\end{array}$ & $\begin{array}{l}\text { S } \\
\text { Office }\end{array}$ & $\begin{array}{l}T \\
\text { Dock }\end{array}$ \\
\hline $\begin{array}{l}\text { Smoke }\left(\mu \mathrm{g} / \mathrm{m}^{3}\right) \\
\mathrm{SO}_{2}\left(\mu \mathrm{g} / \mathrm{m}^{3}\right)\end{array}$ & $\begin{array}{l}\text { (HVS } \\
\text { (Gravimetric } \\
\text { (Reflectance } \\
\text { Titration }\end{array}$ & $\begin{array}{r}168 \\
99 \\
47 \\
30\end{array}$ & $\begin{array}{r}- \\
69 \\
109 \\
43\end{array}$ & $\begin{array}{l}33 \\
23 \\
13 \\
59\end{array}$ & $\begin{array}{l}-\overline{271} \\
117\end{array}$ & $\begin{array}{r}- \\
257 \\
194 \\
77\end{array}$ \\
\hline
\end{tabular}

HVS = High volume samples: weighted means of figures from table 3.

*Indicates alkaline result. 
associated polycyclic aromatic hydrocarbons during the winter months. Whereas we had always avoided the mid-winter months so as to minimise the effects of this background pollution, high concentrations attributable to coal fires had been seen even in April in the earlier series. Concentrations of benzo(a)pyrene were then in the range 200 to $500 \mu \mathrm{g} / 1000 \mathrm{~m}^{3}$, both inside and outside the garage, and nothing of this magnitude has been seen in the present series. If attention is confined to comparisons between samples taken in mid-summer, when background pollution is of lesser importance, then no substantial change is seen in pollution within the garages.

Tables 10 and 11 display results for the samples taken inside the garages in June or July. So far as smoke is concerned, the impression given is of some redistribution of pollution during the day, with no observations quite as high as seen in the peak periods originally (during the evening run-in, in period 2 at Merton or 1 at Dalston), but some evidence of enhanced concentrations at other times (notable during the morning run-out at Merton, period 4, site B). These features relate mainly to changes in operating procedures and sampling points, and since the sites had been chosen specifically to represent the worst possible conditions close to the buses, the results are

Table 10 Comparisons between concentrations of smoke and benzo(a) pyrene at Merton garage, June 1956 and June 1979

\begin{tabular}{llllll}
\hline Period & Site & \multicolumn{2}{c}{ Smoke $\left(\mu \mathrm{g} / \mathrm{m}^{3}\right)$} & \multicolumn{2}{c}{$B a P\left(\mu \mathrm{g} / 1000 \mathrm{~m}^{3}\right)$} \\
\cline { 3 - 6 } & & 1956 & 1979 & 1956 & 1979 \\
\hline 0 & A & - & 800 & - & 6.8 \\
1 & & 810 & 730 & 27 & 6.9 \\
2 & & 1440 & 780 & 26 & 5.9 \\
3 & & 210 & 173 & 11 & 0.6 \\
4 & & - & 584 & - & 13.0 \\
5 & & - & 614 & - & 5.8 \\
4 & B & 480 & 1143 & 5 & 14.0 \\
$0-5$ & C & 205 & 138 & 14 & 0.3 \\
\hline
\end{tabular}

Table 11 Comparisons between concentrations of smoke and benzo(a) pyrene at Dalston garage, June 1957 and July 1979

\begin{tabular}{llllll}
\hline Period & Site & \multicolumn{2}{c}{ Smoke $\left(\mu \mathrm{g} / \mathrm{m}^{3}\right)$} & \multicolumn{2}{c}{$B a P\left(\mu \mathrm{g} / 1000 \mathrm{~m}^{3}\right)$} \\
\cline { 3 - 6 } & & 1957 & 1979 & 1957 & 1979 \\
\hline 0 & $\mathrm{P}$ & - & 154 & - & 0.8 \\
1 & & 550 & 192 & 29 & 1.2 \\
2 & & 270 & 105 & 9 & 1.2 \\
3 & & 140 & 47 & 3 & 0.4 \\
4 & & - & 148 & - & 0.9 \\
5 & & - & 327 & - & 2.3 \\
4 & $\mathrm{Q}$ & 360 & 356 & 23 & $6 \cdot 0$ \\
$0-5$ & $\mathrm{R}$ & 148 & 33 & 13 & 0.1 \\
\hline
\end{tabular}

not necessarily representative of those in the garages $\overline{\bar{O}}$ in general. For benzo(a)pyrene there are equally no figures as high as those seen in peak periods previously. In both garages concentrations appear now to be higher in the morning run-out than in the evening run-in, and at Dalston concentrations are low most of the time. If allowance is made for the background concentrations of smoke and polycyclic aromatic hydrocarbons, as has been done in tables 4 and 5 above, the general conclusion is that there has not been any major change in the contributions made by the buses since our earlier studies, and as is clear from tables 6 and 7, diesel smoke as produced by these buses is a weak source of benzo(a)pyrene as compared with coal smoke.

It must be emphasised that our observations, covering single days only, and limited to a few fixed sites, cannot provide any proper assessment of the exposure of men working in the garage. The figures must be regarded as extreme upper limits, for we sited our main samplers as close as possible to the buses at sites where they were liable to stop with engines running. Only a few men worked at these positions and they were there for only limited periods during their shift. Although some of the highest concentrations of smoke and associated polycyclic aromatic hydrocarbons occurred this time during the morning runout at our supplementary sites in the annex at Merton $\overrightarrow{0}$ or in the corner at Dalston, these were not areas if o which men were working.

The sampling and analytical work was a team effort involving other members of the unit, and we would particularly like to thank Mr C Brown and Mr A G F Brooks for their help. We are indebted to London Transport for the facilities and help offered for this study.

Requests for reprints to: Mr R E Waller, Toxicology and Environmental Protection Division, DHSS, Hannibal House, Elephant and Castle, London SE1 6TE.

\section{References}

${ }^{1}$ Commins BT, Waller RE, Lawther PJ. Air pollution in diesel bus garages. $\mathrm{Br} J$ Ind Med 1957;14:232-9.

${ }^{2}$ Raffle PAB. The health of the worker. Br J Ind Med 1957;14:73-80.

${ }^{3}$ Derrett CJ, Brown C. A continuous-running direct reading sulphur dioxide recorder. $J$ Phys (E) 1978;11:307-10.

${ }^{4}$ Commins BT. A modified method for the determination of polycyclic hydrocarbons. Analyst 1978;83:386-9.

${ }^{5}$ Waller RE. The benzpyrene content of town air. $\mathrm{Br} J$ Cancer 1952;6:8-21.

${ }^{6}$ Stevenson KJ, Apling AJ, Sullivan EJ. Air pollution in homes 3: measurements of carbon monoxide and nitrogen oxides in two liv- 0 ing rooms. Stevenage: Warren Spring Laboratory, 1979. (Report LR 332 (AP).) 